\title{
Childbirth and women's healthcare in pre-modern societies: an assessment
}

\author{
Anna Andreeva $\left({ }^{*}\right)$, Erica Couto-Ferreira $\left({ }^{* *}\right)$ and Susanne Töpfer ( $\left.{ }^{* * *}\right)$ \\ $\left.{ }^{*}\right)$ Karl Jaspers Centre for Advanced Transcultural Studies, Universität Heidelberg \\ andreeva@asia-europe.uni-heidelberg.de \\ $\left.{ }^{* *}\right)$ Cluster of Excellence «Asia and Europe in a Global Context», Karl Jaspers Centre for Advanced \\ Transcultural Studies, Universität Heidelberg, couto-ferreira@asia-europe.uni-heidelberg.de \\ ${ }^{* * *}$ Institute of Egyptology, Universität Heidelberg \\ toepfer@asia-europe.uni-heidelberg.de
}

Dynamis

[0211-9536] 2014; 34 (2): 279-287

http://dx.doi.org/10.4321/S0211-95362014000200001

That childbirth plays a preeminent role in the life of all human groups, communities and societies is obvious to even the casual observer. Few phenomena can be considered so intrinsically fundamental to the ebb and flow of personal and societal life, so universally shared (in the case of infertility, this constitutes yet another thread to the story), and at the same time transcending cultural and geographical borders. Conception, pregnancy and childbirth have not only become an object of study within multiple disciplines, ranging from historical inquiries and the humanities to natural sciences, but they also remain at the forefront of a variety of social, medical and ethical concerns and debates, some of which continue to be political and at times divisive. From this it is clear that although universal, this self-evident human reality and experience does not necessarily account for the variety of cultural and historical interpretations the biological act of childbirth appears to be embedded within.

If childbirth can be taken as the experience shaped by specific cultural contexts, can it be assessed from an historical viewpoint? Could it be possible to identify those elements involved in the construction, experience and management of childbirth that are culture specific, and distinguish them from those which are perceived or conceptualized in comparable ways across cultures? And is it feasible to advance such cross-comparative considerations without trivialising the subject? 
The dossier presented in this special issue emerges from the workshop «Childbirth and Women's Health in Pre-Modern Societies» that took place in Heidelberg in November 2011, and offered different perspectives on how birth and women's health issues related to it were conceptualized and practically dealt with in pre-modern times. The term «pre-modern» is used here without any political intent or value judgment. It refers both to the extended time period that precedes the 16th century BCE and to that expanded set of multiple spatial, chronological, and cultural conditions in which, through a variety of media, the human agents had learnt, transmitted and practised medicine before (or in parallel to) the implementation of the historical scientific discourses that formed the basis for present Western modes of interpretation. The role played by writing and the production of cultural knowledge in the process of conceptualizing, understanding, learning, and managing the complex experience of birth, therefore, is envisioned as a key element in the articulation of the papers presented here.

From a historiographical viewpoint, the five case studies and fields of research represented in this dossier reflect different, although closely related, levels of academic involvement, research agendas and methodological concerns regarding childbirth and women's healthcare. While Ancient Near East and Egyptological studies are still largely anchored in a first phase of research based on the edition and cataloguing of primary sources, inquiries carried out in medieval contexts, whether European or East-Asian, show a greater and more cohesive interest in both the processes of gendering medicine, and the exploration of theoretical and historical aspects of women's healthcare, childbirth and infant care.

The topics of childbirth and women's healthcare have been dealt with in Ancient Near East and Egyptological studies in rather unsystematic and heterogeneous ways. Three main areas of discussion illustrate how its historiography has been approached. First, academic studies have mainly focused on providing philological editions of ancient texts more than on exploring these subjects from the perspectives that the historical method can offer. For the Mesopotamian case, the heterogeneity in publication of cuneiform material, which includes hand copies of cuneiform tablets, has hindered systematic research. The texts available to the scholar, therefore, go from outdated transliterations, partial editions and unpublished or even uncatalogued tablets, to very few, if any, in-depth studies. For its part, ideas on gynaecology, childbirth, and women's health in Egyptology are best understood through a combined analysis of a wealth of sources that have 
been published more systematically than those found in Mesopotamia. These sources comprise medical and magical manuscripts, as well as literary, religious, astronomical and mythological texts; documentary texts; and last but not least, archaeological evidence and iconographical sources from temple walls and birth houses. Second, and concerning a more medico-historical trend, Assyriology and Egyptology have approached a number of very specific issues on fertility, childbirth, women's healthcare and childhood such as generation, foetal formation and its vocabulary ${ }^{1}$; aspects of childhood $^{2}$; contraception and abortion ${ }^{3}$; the conceptualization and treatment of specific ailments ${ }^{4}$; the examination of aetiological agents causing certain women's and children's complaints ${ }^{5}$; and studies on pregnancy and childbirth, from the compilation and organization of textual data ${ }^{6}$, to more comprehensive overviews ${ }^{7}$.

Third, with regard to the application of gender studies tenets to aspects of women's bodies and healthcare, most Ancient Near Eastern

1. Dorman, Peter F. Creation on the Potter's wheel at the eastern horizon of heaven. In: Teeter, Emily; Larson, John A., eds. Gold of praise. Studies on Ancient Egypt in honor of Edward F. Wente. Chicago: Oriental Institute of the University of Chicago; 1999, p. 83-99; Arnaud, Daniel. Le foetus et les dieux au Proche-Orient sémitique ancien. Revue de I'histoire des religions. 1996; 213 (2): 123-142.

2. Feucht, Erika. Das Kind im Alten Ägypten. Die Stellung des Kindes in Familie und Gesellschaft nach altägyptischen Texten und Darstellungen. Frankfurt: Campus Verlag; 1995. See also Robins, Gay. Women in Ancient Egypt. London: British Museum Press; 1993.

3. Biggs, Robert. Conception, contraception and abortion in Ancient Mesopotamia. In: Andrew R. George; Irving L. Finkel, eds. Wisdom, gods and literature: Studies in honour of W.G. Lambert. Winona Lake, Indiana: Eisenbrauns; 2000, p. 1-13. Jean, Richard-Alain; Loyrette, Anne-Marie. À propos des textes médicaux des Papyrus du Ramesseum n. ${ }^{\text {s }}$ III et IV, I: la contraception. Memnonia. 2002; 12-13: 83-115.

4. Steinert, Ulrike. Fluids, Rivers, and Vessels: Metaphors and body concepts in Mesopotamian gynaecological texts. Le Journal des Médecines Cunéiformes. 2013; 22: 1-23; Loyrette, AnneMarie. À propos des textes médicaux des Papyrus du Ramesseum nos III et IV, I: la gynécologie (1). Memnonia. 2004; 15: 67-91. Böck, Barbara. Medicinal plants and medicaments used for conception, abortion, and fertility control in ancient Babylonia. Journal Asiatique. 2013; 301 (1): 27-52.

5. Scurlock, Joann. Baby-snatching demons, restless souls and the dangers of childbirth: Medicomagical means of dealing with some of the perils of motherhood in Ancient Mesopotamia. Incognita. 1991; 2: 135-183; Spieser, Cathie. Avaleuses et dévoreuses: des déesses aux démones en Égypte ancienne. Chronique d'Egypte. 2009; 84: 5-19.

6. Stol, Marten. Birth in Babylonia and the Bible. Its mediterranean setting. Groningen: Styx; 2000.

7. Volk, Konrad. Vom Dunkel in die Helligkeit: Schwangerschaft, Geburt und frühe Kindheit in Babylonien und Assyrien. In: Véronique Dasen, ed. Naissance et petite enfance dans I'Antiquité. Actes du colloque de Fribourg, 28 novembre - 1er décembre 2001. Fribourg: Academic Press; 2004, p. 71-92. 
studies devoted to research of women's issues have unfortunately resisted addressing questions on health, focusing instead visual representation of female nudity, motherhood, infancy and eroticism.

Although previous research has made valuable contributions to the knowledge of Mesopotamian and ancient Egyptian healing practices, the general impression is that of a patchy field where contemporary ideas on gender, health, and disease often eclipse ancient evidence; and where formulations and conceptualizations of pregnancy, childbirth and healthcare often get diluted and swallowed by the waters of generalizing considerations. Besides, Assyriological and Egyptological studies have often taken concepts such as women, gynaecology, and medicine to be univocal, self-evident categories not in need of definition, and equally applicable to any period, source, and historical circumstance, thus promoting generalizing discourses that often obviate processes of change, as well as the possible coexistence of different forms of knowledge.

The studies on childbirth and women's healthcare in pre-modern East Asia published in English have so far concentrated on the history of medicine and gender in pre-modern China (and in many important cases, India and Tibet). However, the field has a considerable potential for elaborating other cultural and historical experiences. Expanding beyond the nationalist and essentialist frameworks, the new studies focus instead on the notions of shared textual traditions and patterns of knowledge transmission across East Asia and beyond ${ }^{8}$. Moreover, the new approaches in cultural history allow an inclusion in this field of the previously neglected medico-religious sphere. Such an approach highlights the impacts of the Buddhist, Daoist, Confucian and other religious and philosophico-naturalist frameworks on the social, cultural, and medical constructions of the female body, as well as the embryological discourse, childbirth and women's healthcare both from a medical and ritual perspective. The new approaches help to address

8. The recent research on Indian and Tibetan medicine and gender proves increasingly relevant, at the very least, for the case of Japan. See, for example, Kritzer, Robert. Childbirth and the mother's body in the Abhidharmakośabhāsya and related texts. In: Indo tetsugaku bukkyōshisō ronshū: Mikogami Eshōkyōju shōju kinen ronshū. Kyoto: Nagata Bunshodo; 2004, p. 10091085; Selby, Martha Ann. Narratives of conception, gestation and labour in Sanskrit Âurvedic texts. Asian Medicine. 2006; 1 (2): 254-275; Garrett, Frances. Religion, medicine and the human embryo in Tibet. London and New York: Routledge; 2008; Suh, Soyong. From influence to confluence: Positioning the history of pre-modern Korean medicine in East Asia. Korean Journal of Medical History. 2010; 19: 225-254. 
culturally specific phenomena and configurations, provide finer narratives of geographical variations in the Indic and Sino-centric cultures of medicine and childbirth, and help mitigate the effects of a dearth or inaccessibility of the surviving East Asian sources and a well-known issue of Sinocentrism ${ }^{9}$.

Starting with Charlotte Furth's research on the formation of the category of fuke (literally, medicine for women) ${ }^{10}$, scholars from America, Hong Kong and Taiwan have established a useful framework of reference from the viewpoints of both medical history and pre-modern China studies ${ }^{11}$. The early Chinese texts from the Qin (c. 221 BCE- 207 BCE) and Han (206 BCE-220 AD) Dynasties underscore the interaction between medicine and ritual in birthing practices. During the Song Dynasty, medicine for women became a separate discipline that placed more emphasis on the regulation of menses as a preamble to maintaining a healthy female body. For this part, Charlotte Furth's 1999 monograph, Shinmura Taku's study on the history of childbirth and reproductive organs and Hitomi Tonomura's research on parturition huts ${ }^{12}$, and more recent (albeit both focusing on the later periods) studies by $\mathrm{Yi}$-li Wu ${ }^{13}$ and Susan Burns ${ }^{14}$, remain definitive guides to the field. Such studies are complemented the relevant research on the history of the body, illness, cultural meaning of the female body,

9. This issue regards the question of how the pre-1700 non-Han cultures, including Japan, Korea and Vietnam, have been mapped and narrated in Anglo-American academia. Suh, n. 8.

10. Furth, Charlotte. Concepts of pregnancy, childbirth, and infancy in Ch'ing Dynasty China. Journal of Asian Studies [Special issue, Women in Qing Period China - A Symposium]. 1987; 46 (1): 7-34. Also, Furth, Charlotte. A flourishing Yin: Gender in China's medical history, 960-1665. Berkeley, Los Angeles: University of California Press; 1999.

11. Raphals, Lisa. The treatment of women in a second-century medical case book. Chinese Science. 1998; 15: 7-23. Leung, Angela Ki Che. Recent trends in the study of medicine for women in Imperial China. Nan Nü. 2005; 7 (2): 110-126; Yates, Robin. Medicine for women in early China: a preliminary survey. Nan Nü. 2005; 7 (2): 127-181; Wilms, Sabine. Ten times more difficult to treat. Nan Nü. 2005; 7 (2): 182-215; Lee, Jender. Childbirth in Early Imperial China. Nan Nü. 2005; 7 (2): 216-286.

12. Shinmura, Taku. Shussan to shokusanchi no rekishi (History of childbirth and reproductive organs). Tokyo: Hôsei Daigaku Shuppanbu; 1995. Tonomura, Hitomi. Birth-giving and avoidance taboo: Women's body versus the historiography of ubuya. Japan Review, 2007; 19: 3-45.

13. Furth, n. 10, 1999; Wu, Yi-Li. Reproducing women: Medicine, metaphor, and childbirth in late Imperial China. Berkeley and Los Angeles: University of California Press; 2010.

14. Burns, Susan, ed. Pregnancy and childbirth in the context of Modernity, US-Japan Women's Journal. 2003; 24; Burns, Susan L. Nanayama Jundô at work: A village doctor and medical knowledge in Nineteenth-Century Japan. East Asian Science, Technology and Medicine. 2008; 29: 61-82 (see especially pp. 78-79). 
detailed examination of medico-religious manuscripts from Dunhuang and Mawangdui, and increasingly, the Buddhist medicine ${ }^{15}$.

By comparison, the field of Medieval European studies has devoted the last three decades to exploring manifold aspects of healing and women's health in the Middle Ages ${ }^{16}$, a period characterised by intense exchange and interaction among communities. The range of issues addressed cover textual editions of primary sources, studies on the transmission of medical and gynaecological works and on editorial processes, mechanisms of vernacularization, medical therapies and uses of materia medica; the relations between miracles, fertility, and childbirth; concepts of abortion; lexicography and vocabulary of the body, physiology, and sexual life; relations between medical texts and the social contexts they are part of; audiences medical texts were addressed; and, most importantly, innovative theoretical approaches to the study of women's healthcare in pre-modern contexts ${ }^{17}$.

The five papers offered in this dossier raise a variety of historical problems and questions that emerge in different cultural settings, but often reveal similar attitudes and patterns with regard to a number of phenomena. What we intend to present, therefore, is a series of snapshots of shifting and often subtly interconnected medical spheres in the multiple cultural and historical contexts of Ancient Near East, medieval Europe and early East Asia. In order to promote a fruitful debate across disciplines, we explore

15. Harper, Donald John. Early Chinese medical literature: the Mawangdui medical manuscripts. London: Kegan Paul International; 1998; Kuriyama, Shigehisa. The expressiveness of the body and the divergence of the Greek and Chinese medicine. New York: Zone Books, 1999; Ko, Dorothy. Every step a lotus: Shoes for bound feet. Berkeley: University of California Press; 2001; Strickmann, Michel. Chinese magical medicine. Stanford: Stanford University Press; 2002; Lo, Vivienne; Cullen, Christopher. Medieval Chinese medicine: the Dunhuang medical manuscripts. London: Routledge Curzon; 2005; Drott, Edward. Gods, Buddhas, and organs: Buddhist physicians and theories of longevity in early medieval Japan. Japanese Journal of Religious Studies. 2010; 3: 247-273. Goble, Andrew Edmund. Confluences of medicine in medieval Japan: Buddhist healing, Chinese knowledge, Islamic formulas, and wounds of war. Honolulu: University of Hawaii Press, 2011. Triplett, Katja. Magical medicine? Japanese Buddhist medical knowledge and ritual instruction for healing the physical body. Japanese Religions. 2012; 37/1-2: 63-92; Salguero, Pierce. Chinese Buddhist medicine: Disease, healers, and the body in cross-cultural translation". Philadelphia: University of Pennsylvania Press, forthcoming 2014.

16. For a thorough bibliographical review, see Green, Monica. Bibliography on medieval women, gender, and medicine (1985-2009), 2010. Digital Library of Sciència.cat website: http://www. sciencia.cat/biblioteca/documents/Green_CumulativeBib_Feb2010.pdf [cited 19 February 2014].

17. For a survey of topics and trends in Medieval women's healthcare, see Monica H. Green, Bodies, gender, health, disease: Recent work on Medieval women's medicine. Studies in Medieval and Renaissance History, 3 2005; 2: 1-46. 
the ways of dealing with pregnancy and birth these cultural realities had, through addressing the same set of historical questions to the diverse sources available for each case study. This set of questions basically explores three aspects related to childbirth in pre-modern societies:

(1) Sources. All papers highlight the processes of the production of knowledge regarding childbirth and women's health, with a special focus on texts. The main research questions the papers have addressed concern: how and where such knowledge is produced, and who is engaged in the process; through what mechanisms such knowledge is gained, adapted, preserved and divulged; which patterns are followed in the processes of its transmission; who writes the texts concerning birth and birth management, and for what purpose.

(2) Attitudes. All papers aim to offer an analysis of ideas, concepts, and attitudes towards pregnancy, childbirth, women's bodies in pregnancy and labour, as well as the representation, conceptualization, and imagining of the unseen, that is, the envisioning of embryological processes that take place within the female body. Key questions here include what the moment of birth represents in a specific culture with relation to the concepts of life, death, (im)purity, etc; whether the specific concepts of time play any role in the act of giving birth; what attitudes are displayed towards the female body and female capacity or incapacity to conceive and give birth.

(3) Management. One of the major concerns for all papers in this dossier is the analysis of practical issues such as who has access to the women in labour. What health problems are likely to emerge during birth, and what are their causes? Who takes care of women during birth, and how do they take care of them? Are there differences in approach among the various professionals involved? What types of intervention (technical manipulation of the body, materia medica employed, rituals and incantations, etc.) came to be documented, and in what media? Where does the birth take place, and is there a specific room or structure specially allocated for this purpose? How is the newborn looked after?

None of these questions, of course, can be answered effectively without a consideration of agency. In this respect, all papers cast light on a variety of specialists involved in the preparation and management of childbirth. Not only is the woman giving birth at the centre of this event but, as seen from a variety of contributions in this issue, it is the female and male relatives, midwives, physicians, members of the public, and religious figures, who are 
closely involved in different tasks, as well as in the events leading to the childbirth itself and its aftermath. With these questions guiding the work we are presenting, the five papers of this dossier cover a variety of case studies ranging from 2nd millennium BCE Egypt to the late medieval period, roughly before the 1600s, covering the cultural and historical contexts of ancient Egypt and Mesopotamia, medieval Europe, and classical and early medieval Japan.

When read together, the aforementioned five papers offer several points for cross-cultural discussion. For example, the role played by writing and the production of cultural knowledge in the process of conceptualizing, understanding, learning, and managing the complex experience of birth represent one of the key elements in the articulation of a significant part of the knowledge related to women's bodies and health. Writing and written evidences, in fact, show a massive predominance of male authorship across cultures (notably, the cases of Ancient Egypt, Mesopotamia, medieval Hebrew sources, and early Japan), appearing as something that seems to transcend the limits offered by the single cases here analysed. Although the male agency, gaze and authority have been well acknowledged as far as the production of written knowledge is concerned, the role of female attendants, midwives, relatives and ritual specialists cannot possibly go unnoticed. The articles that focus on visual representations of labour on temple walls and hand-painted scrolls, literary collections, court diaries, mythological narratives and personalised records demonstrate the involvement of such female attendants much more clearly than the so called «purely medical» texts do. In combining different kinds of evidence, it is possible to recover the fragments of cultural practices, concepts and ideas that were deemed crucial for the successful delivery and sustainability of women's health.

When it comes to the representation of women's bodies and the cultural roles attributed to women, the centrality of reproductive functions (not always conceptualised in positive terms) also emerge as a major theme common to all the papers. The papers encounter certain shared similarities in the conceptualisation and depiction of women's bodies and the act of giving birth (e.g. images of opening, dropping, seeing the light, etc.), but they also display the necessarily significant differences that are embedded and justified within the cultural contexts and respective worldviews.

By focusing on textual evidence, the five papers question the processes of transmission, translation, and adaptation of knowledge about childbirth and women's health over the long spans of time. For example, it becomes 
evident how the Latin texts on gynaecology by Soranus or Muscio were translated and adapted into Hebrew, together with translations of Arab texts and authors, such as Maimonides; experience of childbirth in pre-modern Japan was shaped by the Buddhist ritual practices, Daoist talismans and Chinese medical prescriptions; how the accumulation and circulation of certain strands of medical knowledge was incorporated into the sources in ancient Mesopotamia. The historical sources addressed in the papers demonstrate that the combination of very diverse therapeutic approaches and ritual techniques were perceived as non-discordant but complementary.

\section{Acknowledgements}

Many thanks are owed to our workshop participants and co-presenters: Jessey Choo (Rutgers University), Paolo Delaini (Università di Bologna), Hans-Werner Fischer-Elfert (University of Leipzig), Friedhelm Hoffmann (Ludwig Maximilian University of Munich), and Giulia Pedrucci (Accademia Nazionale dei Lincei Roma). Although, their papers are not included in this special issue, their contribution to it has been invaluable. Special thanks go to Stephan Maul (Assyriology, University of Heidelberg) and Joachim Friedrich Quack (Egyptology, University of Heidelberg) for their kind advice in preparation of the dossier's subsequent drafts, and to Shaun Scally for his assistance with proofreading. 